\title{
Study of Hydraulic Fracturing Real-time Evaluation Technology
}

\author{
Dali Guo ${ }^{1}$, Lei $\mathrm{Xu}^{1, *}$, Xiaohui Zeng ${ }^{2}$, Xijun $\mathrm{Ke}^{1}$ and Bo Tao ${ }^{1}$
}

\author{
${ }^{1}$ State Key Laboratory of Oil and Gas Reservoir Geology and Exploitation, School of Sciences, Southwest Petroleum \\ University, Chengdu, Sichuan, 610500, China; ${ }^{2}$ School of Petroleum Engineering, Southwest Petroleum University, \\ Chengdu, Sichuan, 610500, China
}

\begin{abstract}
Hydraulic fracturing real-time evaluation technology provides an effective way to understand formation and fracturing, assess the quality of fracturing construct, and ensure the safety of fracturing construction. In this paper, combined with numerical simulation and data analysis, a new 3D model of real-time fracture extension is established on the basis of the theories of fluid dynamics, linear elastic fracture mechanics and computational mathematics. This model satisfies the requirement of hydraulic fracturing real-time with the advantage of simple in form, precise and fast in computation. Considering the influence of proppant on the friction calculation of sand mixed fluids, a wellbore flow model is developed, which is more widely used and makes it no need of down-hole data acquisition. The authors also study the related data acquisition technology, and set three ways of acquiring data, which could realize the real-time acquisition of field data. In order to match the real wellhead pressure, an optimizing model and its automatic fitting methods for assessing formation and hydraulic fracturing parameters at real time is proposed. The parameters include fluid rheological properties, leakage levels with dynamic changes, fracture geometry and proppant distribution and migration. The application in Xinjiang oilfield in China showed that the presented technology can satisfy the requirements of fracturing, analyze and evaluate fracturing construction quality and guide fracturing design effectively.
\end{abstract}

Keywords: 3D fracture model, automatic matching method, data acquisition, hydraulic fracturing, real-time evaluation.

\section{INTRODUCTION}

As the first choice of oilfields production increasing and exploration effect improving, hydraulic fracturing plays an increasingly important part in oil and gas field exploration and development. To a large extent, the effect of hydraulic fracturing depends on the understanding of formation and fracture. And hydraulic fracturing real-time evaluation technology is an important way to understand formation and fracture, adjust construction parameters timely, and then improve fracturing effect.

Hydraulic fracture initiation and extension are pressuredependent issues. The changes of pressure during the fracturing process are affected by fracture extension, formation characteristics, fluid properties and fracturing parameters. The hydraulic fracturing real-time evaluation technology can be established based on the relationship of these parameters. The fracture extension, formation characteristics and the fracturing fluids parameters can be determined according to the actual measured pressure information.

Some models have been proposed to obtain the fracture information by analyzing pressure data. Nolte and Smith related trends on the log-log net pressure plot to the evolution of the fracture geometry [1]. The logarithmic curve of the net pressure versus time was introduced to determine the type of fracture induced. The method was developed and

*Address correspondence to this author at the Xindu Avenue 8\#, Xindu District, Chengdu City, Sichuan province, China; Post code: 610500;

Tel: +86 15308004961; E-mail: 1986_xulei@163.com improved by some researchers [2-4] and it had become a classic technique of analyzing fracturing process. However, the above method has some defects: The value of the fracture height should be a definite value; the fracture closure pressure needs to be known in advance, and only a few parameters can be obtained in the fracturing process. The pioneering study of 3D analysis technique was conducted by Crockett et al. [5, 6]. A lumped crack model was proposed, which simplified complex numerical analysis problems to certain functions and integration parameters in database by gamma coefficient and the integral parameters. However, the model is too complicated to be practically applied for real-time evaluation. Furthermore, the parameters change with the fracture location was ignored in the model. With the substantial support provided by the U.S. Department of Energy, a number of relevant theoretical researches and field tests were conducted [7-10]. The most representative ones include the U.S. Gas Research Institute (GRI) field test [11], the model and algorithm put forward by Meyer et al. [12], the pressure historical inversion uniqueness research and the test application in the field conducted by Gulrajani et al. [13, 14], the method of analyzing the pressure historical inversion to obtain formation characteristics (the ground stress differences between the upper, lower layers and the fractured layers) proposed by Piggott et al. [15].

However, there are some common problems exist in the models and methods mentioned above: (1) The fracture closure pressure needs to be given, but to obtain the value is difficult because it changes with the fracture propagation; (2) Very few parameters can be interpreted, and the pressure history inversion methods have significant shortcomings; (3) 
The low-quality of the data collection and slow acquisition speed reduce the construction security.

Based on this, the authors proposed new real-time 3D fracture extension model and the numerical solution procedure, and studied the supporting wellbore flow model and data acquisition technology. The applications in Xinjiang oilfield in China showed that the presented technology can meet the needs of fracturing in time. It helps engineers to analyze and evaluate the quality and safety of treatment, and improve fracturing design level and treatment effects.

\section{REAL-TIME 3-D FRACTURE EXTENSION MODEL}

\subsection{Equation of Volumetric Balance}

During the process of injection work, the flowing fluid in fracture should meet the principle of fluid volumetric balance: the volume of injected fluid $V_{i n j}$ should equal to the summation of fluid loss volume $V_{l s}$ and the fracture volume $V_{f r a c}$. That is

$$
V_{i n j}=V_{l s}+V_{\text {frac }}
$$

Adopting the volumetric balance equation to an arbitrary time interval, namely $t_{n}$ and $t_{n+1}$, the discrete form based on fluid volume balance principal is as follows:

$$
V_{i n j}\left(t_{n}, t_{n+1}\right)=V_{l s}\left(t_{n}, t_{n+1}\right)+V_{\text {frac }}\left(t_{n+1}\right)-V_{\text {frac }}\left(t_{n}\right)
$$

Where, the fluid loss volume [16] in time interval of $t_{n}$ and $t_{n+1}$ can be given by:

$$
V_{l s}\left(t_{n}, t_{n+1}\right)=\gamma_{e} C H_{w} L_{f}\left(\sqrt{t_{n+1}}-\sqrt{t_{n}}\right)
$$

Volume of the fracture at $t_{n}$ can be given by:

$$
V_{\text {frac }}\left(t_{n}\right)=\gamma_{f} L_{f}\left(t_{n}\right) W_{f}\left(t_{n}\right) H_{w}\left(t_{n}\right)
$$

Volume of the fracture at $t_{n+1}$ can be given by:

$$
V_{\text {frac }}\left(t_{n+1}\right)=\gamma_{f} L_{f}\left(t_{n+1}\right) W_{f}\left(t_{n+1}\right) H_{w}\left(t_{n+1}\right)
$$

\subsection{Equation of Fracture Length}

Assume the fracture cross-section is elliptical with the maximum width at a cross section proportional to the net pressure at that point and independent of the width at any other point. The pressure drop equation about power-law fracturing fluid in three-dimensional fracture can be given as:

$$
\frac{\partial p_{f}}{\partial x}=-\left(\frac{16}{3 \pi}\right)^{n^{\prime}} 2^{n^{\prime}+1}\left[\frac{\left(2 n^{\prime}+1\right) q}{n^{\prime} h}\right]^{n^{\prime}} \frac{K}{w^{2 n^{\prime}+1}}
$$

For Newtonian fracturing fluids, the equation can be simplified as:

$$
\frac{\partial p_{f}}{\partial x}=-\frac{64}{\pi} \frac{\mu q}{h w^{3}}
$$

In order to facilitate the data processing and fitting, the dimensionless pressure $p_{D}$ and dimensionless position $x_{D}$ in the fracture are introduced:

$$
\begin{aligned}
& p_{D}=\frac{p_{f}-S_{1}}{p_{w}-S_{1}} \\
& x_{D}=x / L_{f}
\end{aligned}
$$

The pressure distribution in the fracture in propagation process is as follows:

$$
p_{D}=\left(1-x_{D}\right)^{\gamma_{p}}
$$

That is

$$
p_{f}-S_{1}=\left(p_{w}-S_{1}\right)\left(1-x / L_{f}\right)^{\gamma_{p}}
$$

Nolte also introduced parameter $\alpha$ as the ratio of average pressure in the fracture and bottom-hole pressure [2]. The following equation can be derived from definition:

$$
\alpha=\frac{\frac{1}{L_{f}} \int_{0}^{L_{f}}\left(p_{f}-S_{1}\right) d x}{p_{w}-S_{1}}=\frac{1}{\gamma_{p}+1}
$$

According to the above pressure distribution, pressure drop equation starts at the bottom $x=0$ firstly, and then the derivation of pressure distribution in the fracture can be obtained, finally the pressure drop equation can be converted to fracture length equation. For power-law fracturing fluids, the equation of fracture length can be given by:

$$
L_{f}=\frac{\gamma_{p}\left(p_{w}-S_{1}\right)}{\left(\frac{16}{3 \pi}\right)^{n^{\prime}} 2^{n^{\prime}+1}\left[\frac{\left(2 n^{\prime}+1\right) Q}{2 n^{\prime} H_{w}}\right]^{n^{\prime}} \frac{K}{W_{f}^{2 n^{\prime}+1}}}
$$

For Newtonian fracturing fluids, the equation of fracture length can be given by:

$$
L_{f}=\frac{\gamma_{p}\left(p_{w}-S_{1}\right)}{\frac{32}{\pi} \frac{\mu Q}{H_{w} W_{f}^{3}}}
$$

\subsection{Equation of Fracture Width}

Fracture width equation can be solved through England and Green formulas [17]. If the hydraulic fracture is limited in the fractured interval, the maximum width can be given by:

$$
W_{f}=\frac{2\left(1-\gamma^{2}\right) H_{w}}{E}\left(p_{w}-S_{1}\right)
$$

If the hydraulic fracture breaks through to the cover layer or bottom layer, the maximum width can be given by:

$$
\begin{aligned}
W_{f}= & \frac{4\left(1-\gamma^{2}\right) l}{E}\left(p_{w}-S_{1}\right)-\frac{4\left(1-\gamma^{2}\right) l}{\pi E}\left(S_{2}-S_{1}\right) \\
& \left(\cos ^{-1} \frac{z_{a}}{l}-\frac{z_{a}}{l} \ln \frac{l+\sqrt{l^{2}-z_{a}^{2}}}{z_{a}}\right)- \\
& \frac{4\left(1-\gamma^{2}\right) l}{\pi E}\left(S_{3}-S_{1}\right)\left(\cos ^{-1} \frac{z_{b}}{l}-\frac{z_{b}}{l} \ln \frac{l+\sqrt{l^{2}-z_{b}^{2}}}{z_{b}}\right)
\end{aligned}
$$

Where, $l=H_{w} / 2, z_{a}=\left(H_{p}+H_{l}-H_{u}\right) / 2$, $z_{b}=\left(H_{p}-H_{l}+H_{u}\right) / 2$.

\subsection{Equation of Fracture Height}

Equation of fracture height can be derived from the theory of liner elastic fracturing mechanics [17]. If the hydraulic 
fracture breaks through to the cover layer or bottom layer, the stress intensity factors in the cross-section of upper and lower ends of the fracture can be calculated by:

$$
\begin{aligned}
& K_{I 2}=\frac{1}{\sqrt{\pi l}}\left[\int_{l}^{z_{b}}+\int_{b}^{z_{a}}+\int_{a}^{l}\right] p(z) \sqrt{\frac{l+z}{l-z}} d z \\
& K_{I 3}=-\frac{1}{\sqrt{\pi l}}\left[\int_{l}^{z_{a}}+\int_{a}^{z_{b}}+\int_{b}^{-l}\right] p(z) \sqrt{\frac{l-z}{l+z}} d z
\end{aligned}
$$

Make $K_{I 2}=K_{I C 2}, K_{I 3}=K_{I C 3}$, equation (17) and (18) can be arranged as:

$$
\begin{aligned}
\sqrt{\pi l} K_{I C 2}= & \left(S_{3}-S_{1}\right)\left(\sqrt{l^{2}-z_{b}^{2}}-l \arcsin \frac{z_{b}}{l}\right)- \\
& \left(S_{2}-S_{1}\right)\left(\sqrt{l^{2}-z_{a}^{2}}-l \arcsin \frac{z_{a}}{l}\right)+\pi l\left(p_{f}-\frac{S_{2}+S_{3}}{2}\right) \\
-\sqrt{\pi l} K_{I C 3}= & \left(S_{3}-S_{1}\right)\left(\sqrt{l^{2}-z_{b}^{2}}+l \arcsin \frac{z_{b}}{l}\right)- \\
& \left(S_{2}-S_{1}\right)\left(\sqrt{l^{2}-z_{a}^{2}}+l \arcsin \frac{z_{a}}{l}\right)-\pi l\left(p_{f}-\frac{S_{2}+S_{3}}{2}\right)
\end{aligned}
$$

Ignoring the changes of rock fracture toughness in fracturing layer, cover layer and bottom layer, fracture height equation can be given by:

$$
\begin{aligned}
& \left(S_{2}-S_{1}\right) \sqrt{l^{2}-z_{a}^{2}}-\left(S_{3}-S_{1}\right) \sqrt{l^{2}-z_{b}^{2}}=0 \\
& p_{w}-S_{1}=\frac{K_{I C}}{\sqrt{\pi l}}+\frac{S_{2}-S_{1}}{\pi} \cos ^{-1} \frac{z_{a}}{l}+\frac{S_{3}-S_{1}}{\pi} \cos ^{-1} \frac{z_{b}}{l}
\end{aligned}
$$

If the hydraulic fracture is limited in the fractured interval, the equation of fracture height can be given by:

$$
p_{w}-S_{1}=\frac{K_{I C}}{\sqrt{\pi l}}
$$

\subsection{Numerical Method}

The dynamical 3-D fracture extension during fracturing operation is governed by volume balance equation, equation of fracture length, equation of fracture width, and equation of fracture height. The unknown parameters include bottomhole pressure, fracture length, fracture width, and fracture height. In this paper, we introduced the time stepped numerical method for solving these equations. Substituting equation of fracture length, equation of fracture width and fracture height equation into volume balance equation, the problem can be solved by using the method of root extracting approach. The Numerical solution flow chart is as shown in Fig. (1).

\subsection{Wellbore Flow Model}

In the fracture extension model, the bottom-hole pressure is required. However, in many hydraulic fracturing operations, the down-hole sensor may not be installed. In order to apply the real-time evaluation technique in a much broader scope, the model for fluid flow in wellbore is presented in this section. Based on the model, the bottom-hole pressure can be calculated through the measured well-head pressure.

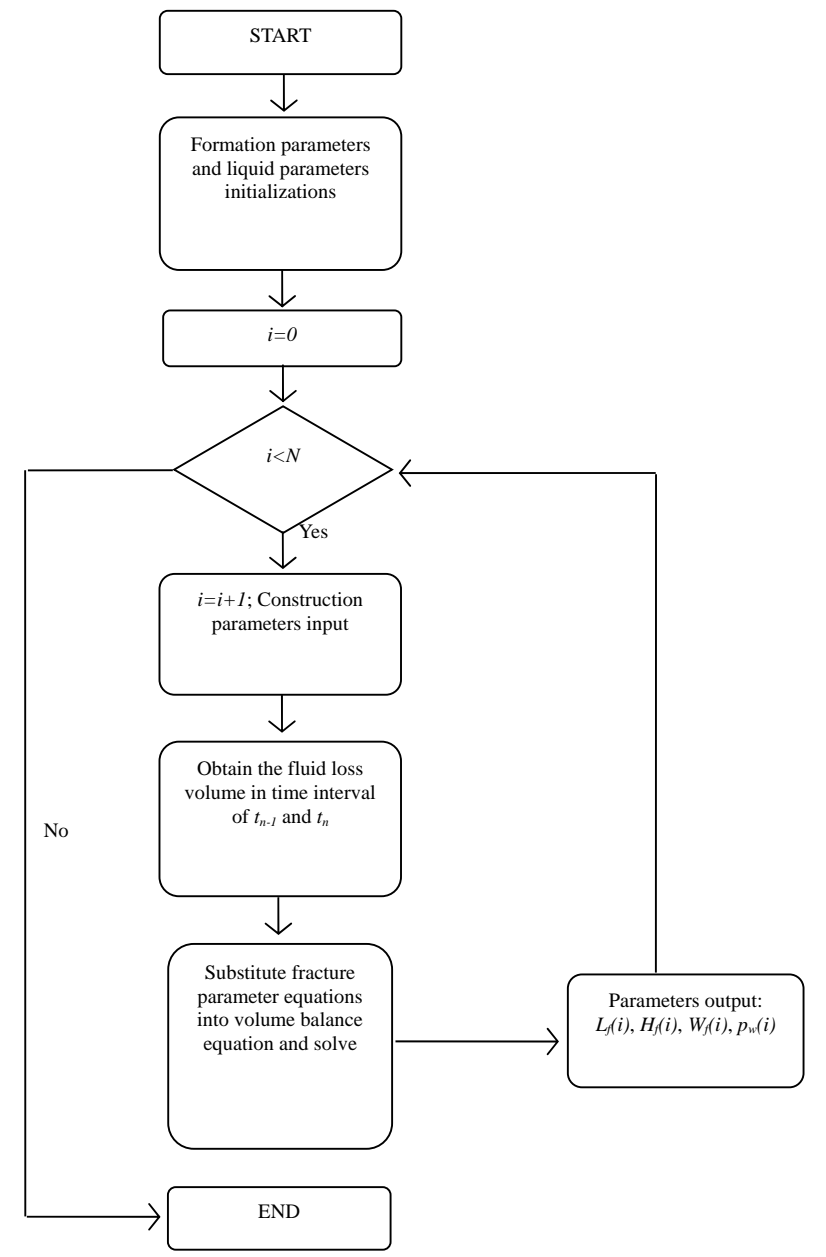

Fig. (1). Numerical solution flow chart.

Integrating the continuity equation, fluid pressure drawdown equation and state equation, wellbore flow equation can be given by:

$$
\begin{aligned}
& \frac{\partial v}{\partial z}=\frac{C_{t} \rho v g-C_{t} \rho f \frac{v^{3}}{2 D}+C_{t} g \frac{\partial p}{\partial t}}{C_{t} \rho v^{2}-g} \\
& \frac{\partial p}{\partial z}=\rho-f \frac{\rho v^{2}}{2 D g}-\frac{\rho v}{g} \frac{\partial v}{\partial z}
\end{aligned}
$$

In order to calculate the friction coefficient $f$, the Reynolds number can be defined as follows:

$$
N_{\mathrm{Re}}=\frac{10000 \rho v D}{\mu}
$$

$$
\begin{aligned}
& \text { When } N_{\mathrm{Re}} \leq 2100, \quad f=64 N_{\mathrm{Re}}^{-1} \\
& \text { When } N_{\mathrm{Re}}>2100, \quad f=0.079 N_{\mathrm{Re}}^{-0.25}
\end{aligned}
$$

It must be noted that the friction coefficient equation mentioned above is applicable only for the pure fracturing fluid, in which proppant is not existed. For the fracturing fluid mixed with proppant, dimensionless modifying friction 
coefficient $f^{\prime}$ (the coefficient ratio of proppant mixed fracturing fluid friction to pure fracturing fluid friction) and dimensionless density $\rho_{D}$ (the density ratio of proppant mixed fracturing fluid to pure fracturing fluid) are introduced. In order to calculate the proppant mixed fluid friction in different density, we have collected a total of 1023 layers data from oil field. These date including wellhead monitoring pressure, proppant mixed fluid density and bottom hole monitoring pressure. Using the method of polynomial fitting, the formula about the two coefficients can be given by:

$$
f^{\prime}=-0.1448 \rho_{D}^{2}+0.1094 \rho_{D}+1.0354
$$

According to field data tests, this formula has been proven to be economical, practical, accurate and reliable.

\subsection{Model Validation}

Microseismic monitoring is an indispensable technology for reservoir fracturing. It can not only indicate the direction and the distribution of fracture, but also provide the fracture Azimuth angle, height, length, asymmetry and extended range etc. In this paper, we used three wells monitoring re-

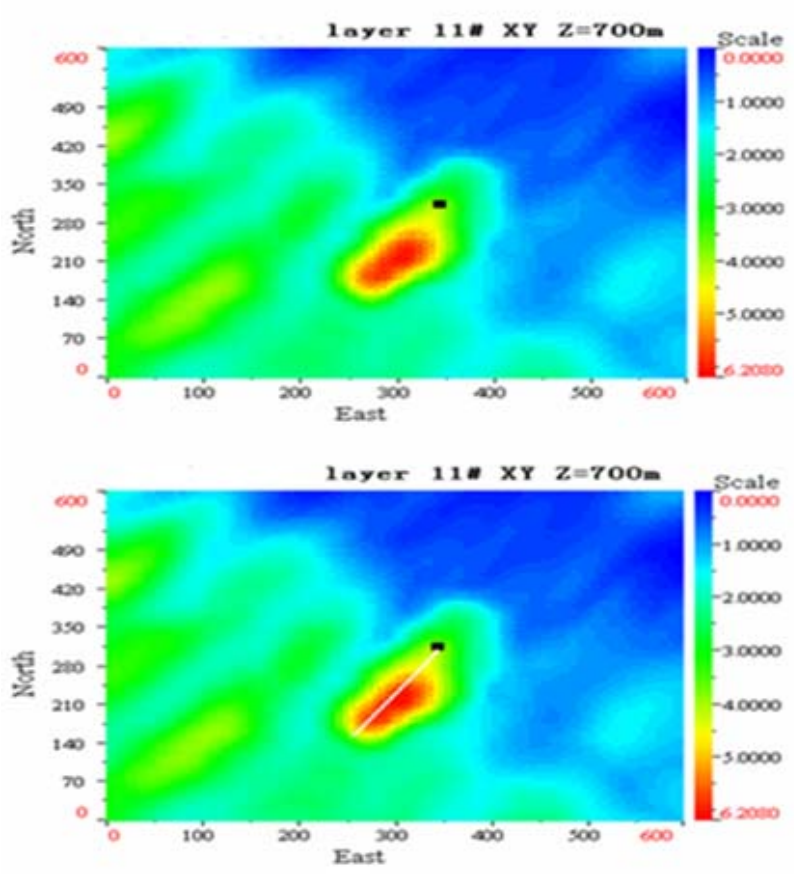

sults form Hancheng Demonstration Zone to verify the accuracy of the model proposed. Fig. (2) shows the 2-D microseismic monitoring scan of well H-8-6. A summary of microseismic monitoring and the real-time evaluation results is listed in Table 1. Table 1 illustrates that the real-time evaluation results are close to that of microseismic results.

\section{REAL-TIME DATA ACQUISITION MODES AND ANALYSIS METHODS}

\subsection{Real-time Data Acquisition Modes}

To meet the requirements of real-time monitoring and analysis, this paper has studied the supporting data acquisition technology. The three data acquisition modes are as follows:

(1) Portable fracture monitor data acquisition mode. The portable fracture monitor can simultaneously monitor two pressure signals, two delivery rate (the main delivery rate and cross-linking delivery rate) signals and two sand signals. Fracturing treatment data acquisition, communication, and data monitoring, recording, playing back can

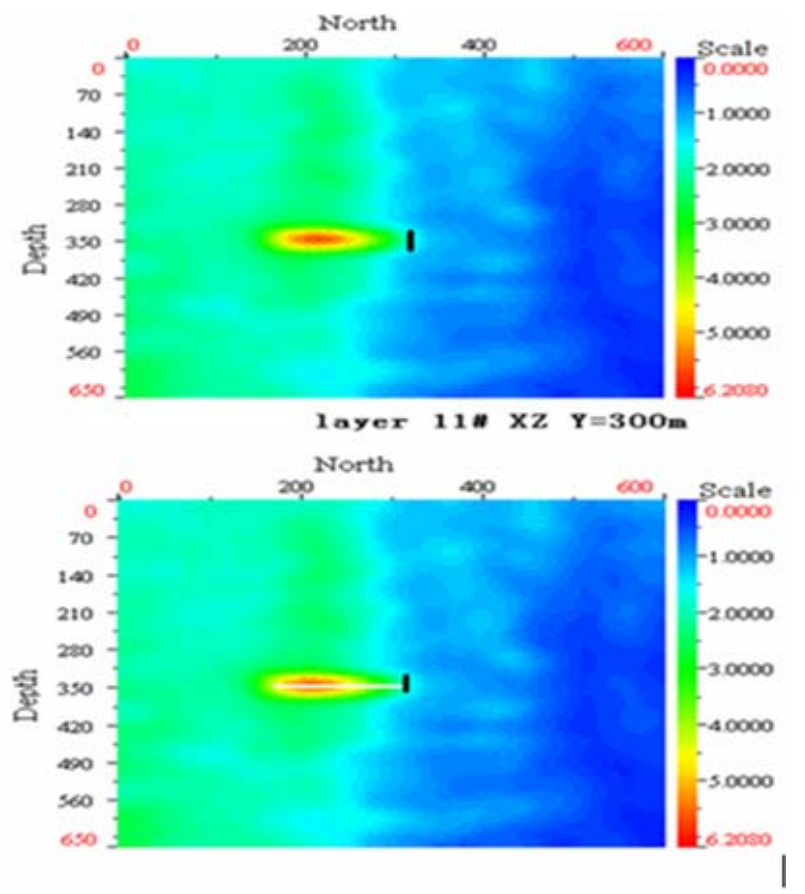

Fig. (2). 2-D Microseismic Monitoring Scan of Well H-8-6.

Table 1. Comparation between analysis results and microseismic results.

\begin{tabular}{|c|c|c|c|c|c|}
\hline Applied technology & Well No & Zone code & Fracture length (m) & Average fracture width (m) & Fracture height (m) \\
\hline \hline The real-time evaluation & H-8-6 & A & 224.76 & 0.0046 & 23.34 \\
\hline Microseismic monitoring & H-8-6 & A & 211.2 & 0.0038 & 22.5 \\
\hline The real-time evaluation & H-15-7 & B & 162.14 & 0.0027 & 0.0024 \\
\hline Microseismic monitoring & H-15-7 & B & 180 & 0.0018 & 19.32 \\
\hline The real-time evaluation & H-10-4 & C & 155.74 & 160.3 & 16.0 \\
\hline Microseismic monitoring & H-10-4 & C & 16015 & \\
\hline
\end{tabular}


Table 2. Analysis results comparison of several interpretation methods.

\begin{tabular}{|c|c|c|c|c|}
\hline Parameter & $\begin{array}{l}\text { The real-time } \\
\text { evaluation }\end{array}$ & $\begin{array}{r}\text { Pressure draw } \\
\text { down analysis }\end{array}$ & $\begin{array}{c}\text { Well temperature } \\
\text { test }\end{array}$ & $\begin{array}{l}\text { Fracturing } \\
\text { simulation }\end{array}$ \\
\hline Minimum horizontal principal stress of fractured layer, $\mathrm{MPa}$ & 24.50 & $\sim$ & $\sim$ & $\sim$ \\
\hline Minimum horizontal principal stress of cover layer, MPa & 28.39 & $\sim$ & $\sim$ & $\sim$ \\
\hline Minimum horizontal principal stress of bottom layer, MPa & 31.04 & $\sim$ & $\sim$ & $\sim$ \\
\hline Fracture toughness of the rock, $\mathrm{MPa} \cdot \mathrm{m}^{0.5}$ & 34.12 & $\sim$ & $\sim$ & $\sim$ \\
\hline Bottom hole fracturing pressure, $\mathrm{MPa}$ & 51.10 & $\sim$ & $\sim$ & $\sim$ \\
\hline Fracture length, $\mathrm{m}$ & 106.82 & 118.7 & $\sim$ & 127.3 \\
\hline Supported fracture length, $\mathrm{m}$ & 63.0 & $\sim$ & $\sim$ & 92.8 \\
\hline Fracture lower height at bottom hole, $\mathrm{m}$ & 7.65 & $\sim$ & 7.2 & 9.34 \\
\hline The average of total fracturing fluid leak-off coefficient, $\mathrm{m} / \mathrm{min}^{0.5}$ & 0.00136 & 0.00094 & $\sim$ & 0.00087 \\
\hline The average of apparent viscosity, MPa.s & 226.45 & $\sim$ & $\sim$ & $\sim$ \\
\hline Fluid efficiency, \% & 22.1 & 13.2 & $\sim$ & 24.6 \\
\hline Closure time, min & $\sim$ & 5.1 & $\sim$ & $\sim$ \\
\hline
\end{tabular}

be conducted by this device. It contains a filter for data preprocessing, which provides high data acquisition accuracy to effectively rule out a variety of random factors, and provides a fast data acquisition speed to meet the requirements of real-time monitoring and analysis.

(2) Serial line data acquisition mode. The 9-pin serial data line and corresponding data acquisition software was developed for fracturing data automatic acquisition in the field. This mode is compatible with a variety of fracturing monitor real-time data transfer in the field and data storage format after the treatment.

(3) Artificial fast input mode. Artificial fast input and data acquisition software has been developed. Special members are arranged to do data input work in the field. This mode is applicable to many types of fracturing monitor.

\subsection{Optimization Model and Data Analysis Methods}

In this paper, the unknown parameters could be obtained based on a hierarchical approach strategy. The whole fracturing process is discrete into time sections and the fracturing fluid rheological parameters and total leak-off coefficient can be obtained dynamically.

In this optimization model, time domain is discrete into time sections. For a time interval from $t_{n}$ to $t_{n+l}$, the independent parameters can be expressed in form of vector:

$$
\beta=\left(K_{I C}, S_{1}, S_{2}, S_{3}, \mu\left(t_{n}\right), C\left(t_{n}\right)\right)^{T}
$$

Take real measured wellhead pressure during the period of $t_{n}$ to $t_{n+1}$ as the fitting target. The least square form of objective function can be given as:

$$
J(\beta)=\sum_{t_{n} \leq t_{i} \leq t_{n+1}}\left(p_{w}^{c a l}\left(t_{i}, \beta\right)-p_{w}^{o b s}\left(t_{i}\right)\right)^{2}
$$

Because the optimizing process and interpreted results must match the actual situation, the independent parameters must be constrained to surmount the multi-solution characteristic. That is, pre-given two values of upper and lower bound $\beta_{\min }$ and $\beta_{\max }$, these parameters should meet that:

$$
\beta_{\text {min }} \leq \beta \leq \beta_{\text {max }}
$$

Through study and practice, stepwise linear square method and constrained variable metric method $[18,19]$ were used to solve the above optimal method. Since common optimization method is apt to mistake local optimum as global optimum, two independent searches are introduced. Only if both of them converge into the same results, it can be considered as the final outcome.

\section{APPLICATION}

An actual field case was used to test the performance of proposed method in Xinjiang oil field. It used on about 60 wells and the error is less than $10 \%$ that compared with other interpretation methods.

Take the well CAI-003 in Xinjiang oil field as an example, the automatic matching results are reasonable, compared the real-time data with fitted data (Fig. (3)). Fig. (4) shows the real-time $3-\mathrm{D}$ fracture extension results, including the length of fracture, length of supported fracture, upper and lower height of fracture and width of fracture. The dynamic performance of fracturing fluid capability is shown in Fig. (5). Compared with the technique proposed by Crockett 


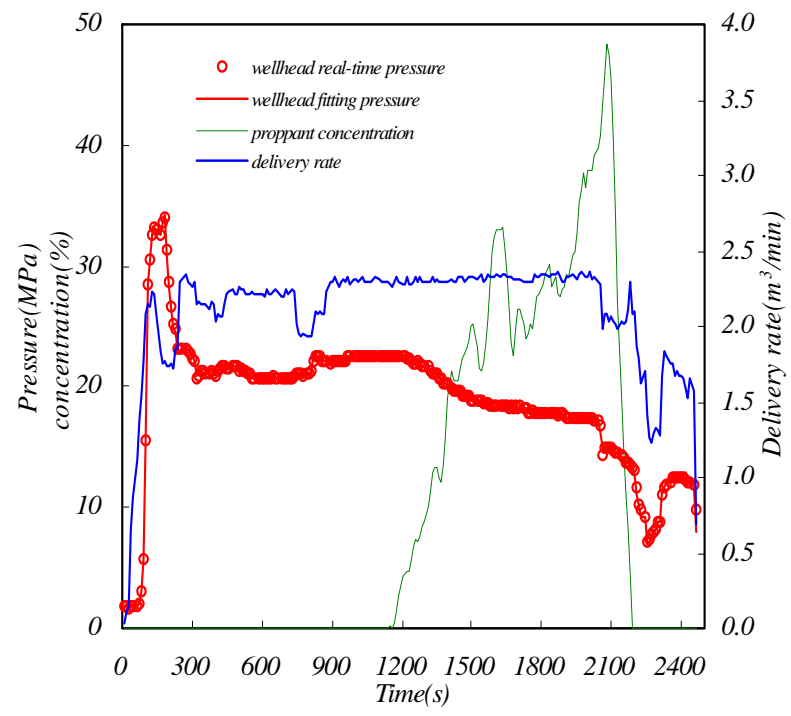

Fig. (3). Situation of real-time data and fitting data.

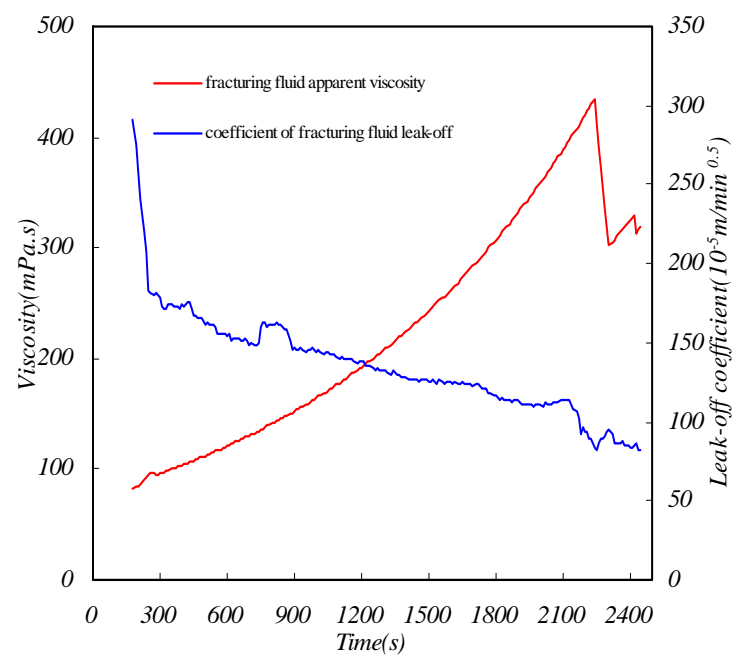

Fig. (5). Dynamic changes of fracture fluid characteristics.

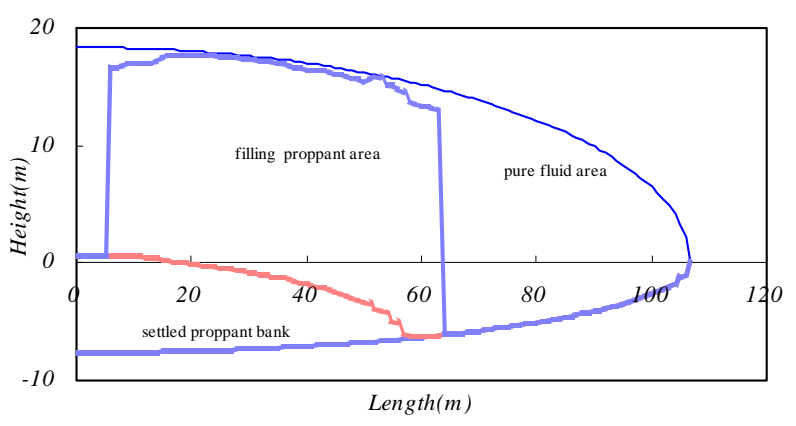

Fig. (7). Section of sand bank at the end of treatment.

[6], an automatic matching method has been used to interpret the performance of fracturing fluid in time. According to Fig. (6) and Fig. (8), the possibility of sand plugging can be estimated in real-time. It can help engineers to take necessary measures before sand plugging and reduce fracturing risk.

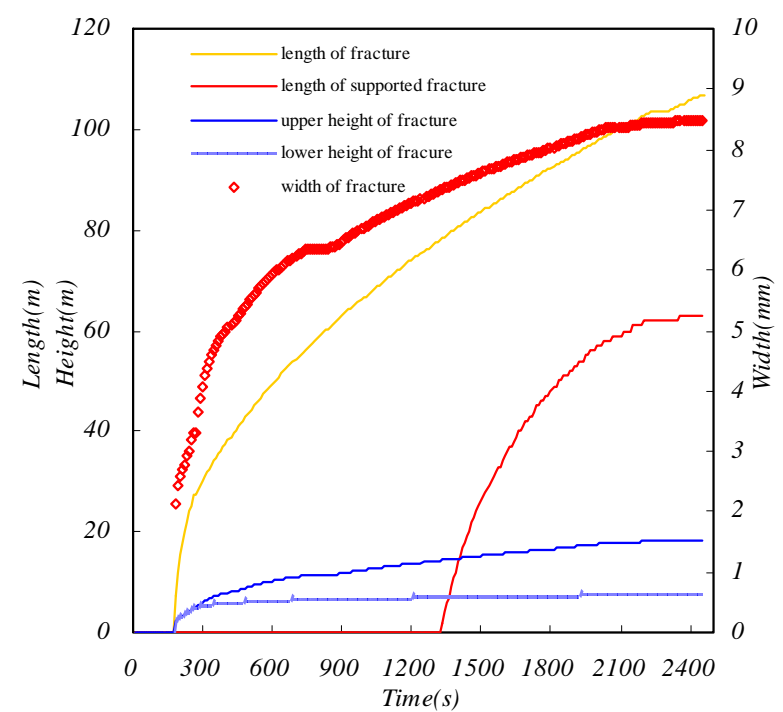

Fig. (4). Situation of 3-D fracture extension.

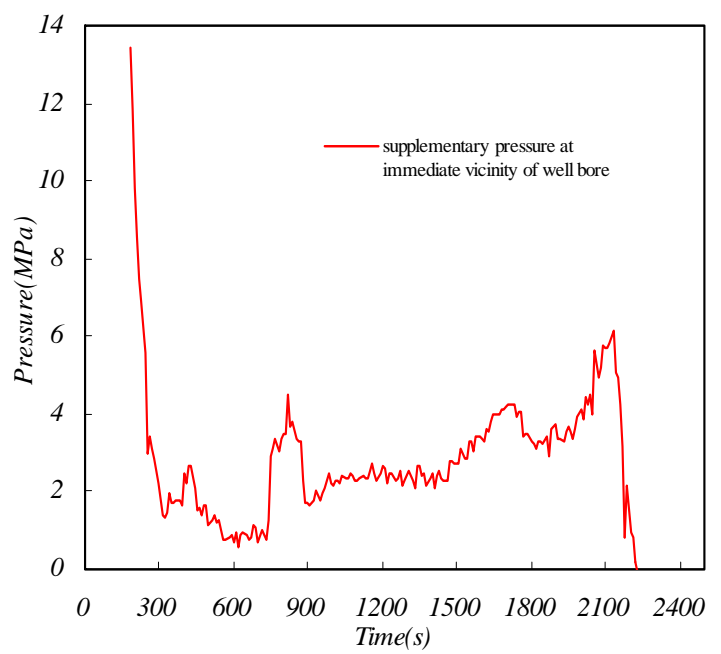

Fig. (6). Supplementary pressure changes at immediate vicinity of well-bore.

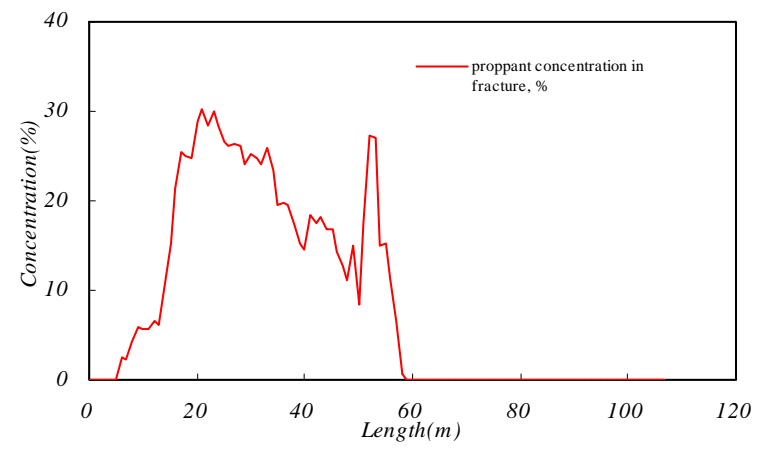

Fig. (8). Sand concentration in fracture at the end of treatment.

In this paper, we compared the real-time evaluation results with pressure draw down analysis results [16], fracturing simulation results [17], and temperature testing results (Table 2). It can be seen that the real-time evaluation results are close to that of other method. Fracture height, for example, the average relative error between the real-time evalua- 
tion values and temperature testing values is $5.87 \%$. For fracture length, the average relative error is $13 \%$. For Fluid efficiency, the average relative error is greater than $30 \%$. The main reason is that pressure draw down analysis method assumes that the fracture height is fixed; ignore the spurt loss and the extension of fracture after pump off. Compared with other methods the new method can interpret more parameters and have advantage in early warning. It can assist engineers to analyze and evaluate the quality and safe of treatment, and improve fracturing design level and treatment effects.

\section{CONCLUSION}

A new real-time 3D hydraulic fracture extension model has been proposed, mainly including the volume equilibrium equation, fracture length equation, fracture width equation, and fracture height equation. Simple and practical numerical methods for these equations are proposed in this paper.

Considering the influence of proppant on the calculation of sand mixing fluid friction, a new wellbore flow model is established. Bottom hole data collecting is dispensed with in this new method which has a wider range of application.

This paper has studied the supporting data acquisition technology. Three data acquisition modes are established: portable fracture monitor data acquisition mode, serial line data acquisition mode and artificial fast input mode.

In order to match the real wellhead pressure, the automatic fitting methods for real-time evaluation of formation and fracture parameters have been proposed. It can explain some critical formation characteristics parameters, such as fracture toughness of rock, ground stress, fracturing pressure, etc. It can also explain fluid rheological properties, leakage levels and its dynamic changes. Meanwhile, 3D hydraulic fracture extension, proppant distribution and migration can also be explained in real time.

\section{CONFLICT OF INTEREST}

The authors confirm that this article content has no conflict of interest.

\section{ACKNOWLEDGEMENTS}

This research is supported by the National Science and Technology Major Demonstration Project 19 (2011ZX05062-008).

\section{NOMENCLATURE}

$C=$ Total fracturing fluid leak-off coefficient, $\mathrm{m} / \mathrm{s}^{0.5}$

$C_{t}=$ Fluid compressibility, $1 / \mathrm{MPa}$

$D=$ Well-bore diameter, $\mathrm{m}$

$E \quad=$ Elastic modulus of the rock, $\mathrm{MPa}$

$f \quad=$ Well-bore friction coefficient, dimensionless

$g=$ Gravity acceleration, $9.81 \mathrm{~m} / \mathrm{s}^{2}$

$H_{l} \quad=$ Lower height of the fracture at bottom hole, $\mathrm{m}$

$H_{p}=$ Height of the fracturing layer, $\mathrm{m}$

$H_{u} \quad=$ Height of the fracture upper at bottom hole, $\mathrm{m}$
$H_{w}=$ Height of the fracture at bottom hole, $\mathrm{m}$

$K=$ Fracturing fluid consistency coefficient, $\mathrm{MPa} \cdot \mathrm{s}^{n^{\prime}}$

$K_{I C}=$ Fracture toughness of fractured layer rock, $\mathrm{MPa}$. $\mathrm{m}^{0.5}$

$K_{I C 2}=$ Fracture toughness of cap layer rock, $\mathrm{MPa} \cdot \mathrm{m}^{0.5}$

$K_{I C 3}=$ Fracture toughness of bottom layer rock, $\mathrm{MPa}$. $\mathrm{m}^{0.5}$

$L_{f} \quad=$ Length of single wing fracture, $\mathrm{m}$

$n^{\prime} \quad=$ Fluid flow pattern index, dimensionless

$p=$ Well-bore pressure, $\mathrm{MPa}$

$p_{f} \quad=$ Pressure of arbitrary point in fracture, $\mathrm{MPa}$

$p_{u}^{c a l}=$ Computed wellhead pressure, $\mathrm{MPa}$

$p_{u}^{o b s}=$ Measured wellhead pressure, $\mathrm{MPa}$

$p_{w}=$ Bottom hole pressure, $\mathrm{MPa}$

$Q=$ Wellhead injection rate during fracture treatment, $\mathrm{m}^{3} / \mathrm{s}$

$S_{1}=$ Horizontal minimum principal stress of the fractured layer, $\mathrm{MPa}$

$S_{2}=$ Horizontal minimum principal stress of the cover layer, $\mathrm{MPa}$

$S_{3}=$ Horizontal minimum principal stress of the bottom layer, $\mathrm{MPa}$

$v=$ Flow rate of the fluid in well-bore, $\mathrm{m} / \mathrm{s}$

$W_{f} \quad=$ Width of the fracture at bottom hole, $\mathrm{m}$

$\gamma=$ Poisson ratio of the rock, dimensionless

$\gamma_{e}=$ Fracture extension index, dimensionless

$\gamma_{f}=$ Fracture geometry factor, dimensionless

$\gamma_{p}=$ Pressure distribution index in the fracture, dimensionless

$\mu \quad=$ Viscosity of fracturing liquid, $\mathrm{MPa} \cdot \mathrm{s}$

$\rho=$ Density of sand mixing fracturing fluid, $\mathrm{kg} / \mathrm{m}^{3}$

$q=$ Fluid flow in the fracture, $\mathrm{m}^{3} / \mathrm{s}$

$h=$ The height in any position in the fracture, $\mathrm{m}$

$w \quad=$ The width in any position in the fracture, $\mathrm{m}$

\section{REFERENCES}

[1] K.G. Nolte, and M.B. Smith, "Interpretation of fracturing pressures", Journal of Petroleum Technology, vol. 33, pp. 1767-1775, 1981.

[2] K.G. Nolte, "Determination of proppant and fluid schedules from fracturing pressure decline", Society of Petroleum Engineers Production Engineering, vol. 1, pp. 255-265, 1986.

[3] K.G. Nolte, "Fracturing pressure analysis for non-ideal behavior", Journal of Petroleum Technology, vol. 43, pp. 210-218, 1991.

[4] J.A. Ayoub, J.E. Brown, R.D. Barree, and J.J. Elphick, "Diagnosis and evaluation of fracturing treatments", SPE Production Engineering, vol. 7, pp. 39-46, 1992.

[5] A.R. Crockett, N.M. Okusu, and M.P. Cleary, "A complete integrated model for design and real-time analysis of hydraulic fracturing operations", SPE California Regional Meeting, Oakland, California USA, pp. 2-4, 1986 
[6] A.R. Crockett, R.M. Willis, and M.P. Cleary, "Improvement of hydraulic fracture prediction by real-time history matching on observed pressures", Society of Petroleum Engineers Production Engineering, vol. 4, pp. 408-416, 1989.

[7] M.P. Cleary, A.M. Burharali, A.R Crockett, and A.M. Burharali, "Computerized field system for real-time monitoring and analysis of hydraulic fracturing operations", International Meeting on Petroleum Engineering, pp. 17-20, 1986.

[8] A.M. Buharali, T.B. Wright, and R.M. Willis, "Real-time hydraulic fracturing simulation using a portable microcomputer", Petroleum Industry Application of Microcomputers, pp. 23-26, 1987.

[9] C.M. Pearson, "Development and application of an operator's stimulation monitoring system", SPE Annual Technical Conference and Exhibition, Dallas, Texas, USA, pp. 27-30, 1987.

[10] D.E. Johnson, C.A.W.A. Stachel, H. Schmidt, and M.P. Cleary, "On-site real-Time analysis allows optimal propped fracture stimulation of a complex gas reservoir", SPE Production Operations Symposium, Oklahoma City, Oklahoma, USA, pp. 21-23, 1993.

[11] B.M. Robinson, S.A. Holditch, and R.E. Peterson, "The gas research institute's second staged field experiment: a study of hydraulic fracturing", SPE Gas Technology Symposium, Houston, Texas, USA, pp. 22-24, 1991.

[12] B.R. Meyer, G.D. Cooper, and S.G. Nelson, "Real-time 3-D hydraulic fracturing simulation: theory and field case studies", SPE Annual Technical Conference and Exhibition, New Orleans, Louisiana, USA, pp. 23-26, 1990.
[13] S.N. Gulrajani, M.G. Mack, and J.L. Elbel, "Pressure history inversion for interpretation of fracture treatments", Society of Petroleum Engineers Production \& Facilities, vol. 13, pp. 258-266, 1998.

[14] S.N. Gulrajani, K.G. Nolte, and J. Romero, "Evaluation of the msite b-sand experiments: the evolution of a pressure analysis methodology", SPE Annual Technical Conference and Exhibition, San Antonio, Texas, USA, pp. 5-8, 1997

[15] A.R. Piggott, B.H. Brady, and H. Gu, "Reservoir formation characterization from hydraulic fracturing records", Proceeding Eurock'92 Symposium, London, UK, pp. 360-365, 1992.

[16] D.L. Guo, J.Z. Zhao, J.C. Guo, and X.H. Zeng, "Three-dimensional model and mathematical fitting method of pressure test data after fracturing", Natural Gas industry, vol. 21, pp. 49-52, 2001.

[17] D.L. Guo, L.J. Ji, J.Z. Zhao, and C.Q. Liu, "3D fracture propagation simulation and production prediction in coalbed", Applied Mathematics and Mechanics, vol. 22, pp. 337-344, 2001.

[18] D.L. Guo, C.Q. Liu, and J.Z. Zhao, "Dynamic production prediction and parameter identification for gas well with vertical fracture", Applied Mathematics and Mechanics, vol. 23, pp. 563-568, 2002 .

[19] D.L. Guo, X.H. Zeng, J.Z. Zhao, and C.Q. Liu, "Model and method of well test analysis for wells with vertical fracture", Applied Mathematics and Mechanics, vol. 26, pp. 527-533, 2005.

Received: March 31, 2014

Revised: July 18, 2014

Accepted: August 18, 2014

(C) Guo et al.; Licensee Bentham Open.

This is an open access article licensed under the terms of the Creative Commons Attribution Non-Commercial License (http://creativecommons.org/licenses/by-nc/3.0/) which permits unrestricted, non-commercial use, distribution and reproduction in any medium, provided the work is properly cited. 